\title{
Judgment of covariation in classical and instrumental conditioning contexts
}

\author{
JAMES O. BENEDICT \\ James Madison University, Harrisonburg, Virginia
}

\begin{abstract}
College students judged the covariation of noncontingent events in both classical and instrumental conditioning contexts. The type of early contingency and the overall probability of events were varied. The subjects rated the covariation higher in the instrumental conditioning context and in conditions in which the probability of events was higher. The type of early contingency did not consistently affect the magnitude of the ratings. It appeared that the act of responding increased the ratings of covariation in noncontingent situations.
\end{abstract}

Dickinson, Shanks, and Evenden (1984) showed that human subjects are able to judge act-outcome contingencies when they are given sets of trials in which responses are made and outcomes are observed in a video game format. Subjects were given trials in which the $P$ (outcome $\mid$ action) and the $P$ (outcome $\mid$ no action) were fixed. When the difference showed a positive contingency (e.g., 75-25), the subjects identified the overall contingency as being positive (the average rating was 50 on a scale of -100 to +100 ). When the difference showed a negative contingency (e.g., 25-75), the subjects identified the overall contingency as being negative (the average rating was -40 ). But most interesting for the present paper were the conditions with equal conditional probabilities (e.g., 75-75 or 25-25). Dickinson et al. (1984) found that subjects rated the contingency in the 75-75 condition positive, with an average rating of 22; in the 25-25 condition, they rated it below zero, at -12 . Alloy and Abramson (1979), who used the same two noncontingent conditions, obtained similar ratings.

Using rats, Benedict and Ayres (1972) also found that under certain conditions, rats acquired an association between a tone CS and a shock US after exposure to overall noncontingent conditioning sessions. Specifically, they found that if an early positive contingency existed between the CS and the US, the rats later showed conditioned suppression to the CS. Likewise, if an early negative contingency occurred, no conditioned suppression was shown.

While Benedict and Ayres' (1972) and Rescorla's (1968) early work on contingency theory was carried out with a classical conditioning procedure, most of the human work on contingency judgment has been done with an instrumental conditioning procedure.

In the present experiment, college students were the subjects. There were three purposes. The first was to determine whether the ratings of contingency would be

Correspondence should be addressed to James O. Benedict, Department of Psychology, James Madison University, Harrisonburg, VA 22807. different after exposure to a classical as opposed to an instrumental contingency. It was hypothesized that the act of responding would serve to increase the perceived rating of control in a noncontingent situation. The second purpose was to replicate Benedict and Ayres (1972), to show that in a noncontingent situation, a greater perception of a relationship - that is, a higher covariation-would be indicated following an early positive contingency than would be indicated following an early negative contingency, both in a classical and in an instrumental conditioning context. The third purpose was to replicate and extend the findings of Dickinson et al. (1984). Thus, it was expected that subjects would make higher ratings of covariation after conditions with a positive contingency than they would after conditions with no contingency, and that higher ratings would be made in noncontingent conditions with higher probability of actions and outcomes. It was also hypothesized that these findings would occur not only in an instrumental conditioning context like that which Dickinson et al. (1984) had used, but also in a classical conditioning context.

\section{METHOD}

\section{Subjects}

Thirty-three college students (12 male and 21 female), with an age range of 18-24 years, served as subjects and received class credit for participation in the department subject pool.

\section{Procedure}

After having arrived in the experimental setting, each student was informed about the experiment and was asked to sign a consent form. If consent was given, the student was seated in front of an Apple Ile computer with monochrome monitor and was read the following instructions.

In this experiment, you will be presented two different types of problems: Watch problems and Response problems. On the Response problems your task is to find out whether tapping the SPACE BAR has any effect on the occurrence of a tone. At any time you may choose to tap the SPACE BAR or not tap it. You may tap the key as many times as you like, or you may refrain from tapping it for as long as you like. However, because of the nature of the task, it is to your advantage to tap the SPACE BAR some of the time and not tap some of the time. In order to make accurate estimates, you must know what happens when you tap the SPACE BAR and when you don't tap it. 
In addition, because your task is to find out whether tapping the key has any effect on the occurrence of the tone, please do not hold the key down at any time during the Response problems.

On the Watch problems your task is to find out whether a stimulus light in any way predicts the occurrence of the tone. Do not tap the SPACE BAR on these trials because you only need to watch for the stimulus light and listen for the tone.

I would like you to try 10 different problems: five Watch problems and five Response problems. Each problem will be a few minutes long. In each case your task will be to find out whether tapping the SPACE BAR on the Response problems has an effect on the occurrence of the tone or whether the stimulus light on the Watch problems predicts the tone.

Each problem will begin with the instructions: Press RETURN to begin, and will end with the statement: End of Problem, Press RETURN. After each Response problem, enter the number anywhere between -100 and +100 that best characterizes the degree to which tapping on the SPACE BAR affected the occurrence of the tone from "prevents the tone from occurring" $(-100)$ to "causes the tone to occur"' $(+100)$. After each Watch problem, enter the number anywhere between -100 to +100 that best characterizes the degree to which the stimulus light relates to the tone from "predicts the absence of tone" $(-100)$ to "predicts the presence of tone" $(+100)$.

In addition, because the problems differ from one another, it is important that you not let your judgment on any given problem affect your judgment on any of the other problems.

The problems will be separated by $30 \mathrm{sec}$ to allow you time to make ratings. After you enter your number for the tenth and last problem, the computer will print: You are finished.

The tone was a 1000-Hz 1-sec tone generated by the computer. A shaded rectangle, approximately $1 \times 2 \mathrm{~cm}$, was presented simultaneously with the tone and had the word "TONE" embedded in it with reverse video. The stimulus light was also a shaded rectangle, approximately $2 \times 4 \mathrm{~cm}$, which remained on the screen for 2 sec and had the word "STIMULUS" embedded in it with reverse video. The five response and five watch problems were given in a different counterbalanced order to each of the subjects. The values of the variables for each of the problems can be seen in Table 1 .

Eight of the problems demonstrated an overall noncontingent relationship. Of these eight, the classical conditioning or watch problems differed in the probability of CS and US; the instrumental conditioning or response problems differed in the probability of response and outcome. The problems also varied in the type of early contingency. The two different levels of early contingency and the two levels of probability of events were replications of conditions used by Benedict and Ayres (1972). The other two problems showed an overall positive contingency of $P(\mathrm{US} \mid \mathrm{CS})=.9$ and $P(\mathrm{US} \mid$ no CS $)=.2$ in the watch problem and $P$ (outcome $\mid$ response) $=.9$ and $P$ (outcome $\mid$ no response) $=.2$ in the response problem. Each of the five response problems was completed only after the predetermined $P(\mathrm{R})$ and $P$ (outcome) was achieved for the nominal 200-sec session length.

\section{RESULTS AND DISCUSSION}

When the results of the positive contingent and noncontingent conditions were compared, the average rating of the two positive contingent conditions was significantly higher than that of any of the noncontingent conditions $(p s<.001)$. The means and standard deviations are shown in Table 1 . The subjects seemed to be sensitive to the overall contingency by indicating a greater covariation of events in the two positive contingent problems than in the eight noncontingent problems. These results were found in both the watch problems and the response problems, and they appear to replicate the findings of Dickinson et al. (1984), who used an instrumental conditioning context, and to extend their findings to a typical classical conditioning context.

The results of the noncontingent conditions were analyzed with a 2 (early contingency) $\times 2$ (CS/US or response/outcome probability) $\times 2$ (watch/response) within-subjects analysis of variance. A significant interaction between the type of early contingency and probability was found $[F(1,32)=8.75, p<.006]$. The means relevant to this interaction are shown in Figure 1.

Further analysis of the interaction revealed that subjects rated the $.66-.26$ conditions higher on the early positive contingency problems than on the early negative contingency problems $(p<.025)$. No difference was found for the $.66-.66$ conditions. The results of the $.66-.26$ conditions replicate the findings of Benedict and Ayres (1972), who used a conditioned suppression paradigm. The main effect of probability of CS and US or response and outcome was significant $[F(1,32)=80.45, p<$ $.0001]$. The subjects gave overall higher ratings to the problems with higher probabilities of accidental pairings. This supports Dickinson et al.'s (1984) finding that subjects who responded to two noncontingent conditions rated the condition with more accidental pairings higher than the one with a smaller number of accidental pairings.

A large main effect for the noncontingent problems was found for the watch/response variable $[F(1,32)=24.79$, $p<.0001]$. The subjects made higher ratings on the

Table 1

Conditions of Experiment and Average Ratings

\begin{tabular}{|c|c|c|c|c|c|c|}
\hline \multirow{3}{*}{$\begin{array}{c}P(\mathrm{CS}) \text { or } \\
P(\text { Response) } \\
\end{array}$} & \multirow{3}{*}{$\begin{array}{c}P(\text { US }) \text { or } \\
P(\text { Outcome })\end{array}$} & \multirow{3}{*}{$\begin{array}{c}\text { Contingency } \\
\text { Conditions } \\
\end{array}$} & \multicolumn{4}{|c|}{ Problem Type } \\
\hline & & & \multicolumn{2}{|c|}{ Watch } & \multicolumn{2}{|c|}{ Response } \\
\hline & & & $M$ & $S D$ & $M$ & $S D$ \\
\hline \multicolumn{7}{|c|}{ Noncontingent Conditions } \\
\hline $\begin{array}{l}.66 \\
.66 \\
.66 \\
.66\end{array}$ & $\begin{array}{l}.26 \\
.26 \\
.66 \\
.66\end{array}$ & $\begin{array}{l}\text { Early Negative } \\
\text { Early Positive } \\
\text { Early Negative } \\
\text { Early Positive }\end{array}$ & $\begin{array}{r}-35.0 \\
-10.6 \\
9.4 \\
6.5\end{array}$ & $\begin{array}{l}46.3 \\
40.3 \\
27.2 \\
35.9\end{array}$ & $\begin{array}{r}-11.3 \\
-1.03 \\
46.7 \\
40.1\end{array}$ & $\begin{array}{l}41.8 \\
35.6 \\
29.3 \\
24.5\end{array}$ \\
\hline \multicolumn{7}{|c|}{ Positive Contingent Condition } \\
\hline .66 & .66 & $\begin{array}{l}P(\mathrm{US} \mid \mathrm{CS})=.90 \\
P(\mathrm{US} \mid \text { no CS })=.20\end{array}$ & 63.6 & 40.2 & 88.1 & 10.0 \\
\hline
\end{tabular}

Note-To determine the frequency of events, each of the conditions was divided into 1002 -sec intervals. 


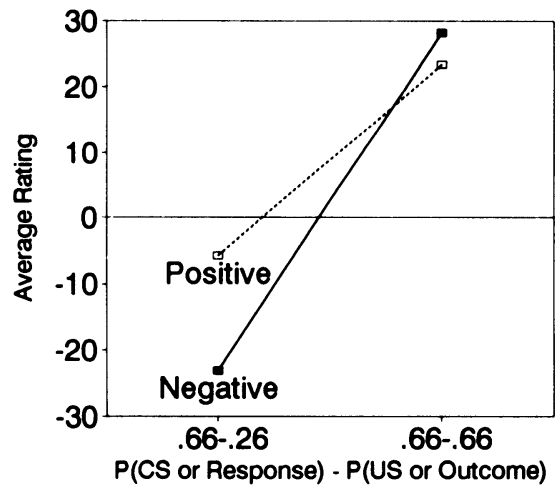

Figure 1. The average ratings for the interaction between type of early contingency and probability of events.

response problems $(M=18.62)$ than they did on the watch problems $(M=-7.41)$.

In general, the results tend to support the earlier work of Benedict and Ayres (1972), who found that subjects are sensitive to an early contingency especially if the overall probability of chance pairings is relatively small. In the $.66-.26$ problems, the probability of a chance pairing was .17 ; in the $.66-.66$ problems, the probability of a chance pairing was .44 .

The results also show that when slibjects are asked to respond on noncontingent problems, they overestimate the relationship between their responses and the outcomes.
Most of the research on human covariation has been done with instrumental conditioning as the context (e.g., Alloy \& Abramson, 1979; Dickinson et al., 1984; Neunaber \& Wasserman, 1986). The act of responding seems to bias subjects and influences their covariation judgments. The use of a classical conditioning context, in which subjects are asked simply to watch events, seems to eliminate the bias that causes subjects to make judgments that correspond more closely to the physical covariation of the events. Subjects are more accurate at identifying the covariation of two events after watching these events occur than they are when one of the two events is an initiated event (i.e., the response made by the subject).

\section{REFERENCES}

Alloy, L. B., \& Abramson, L. Y. (1979). Judgement of contingency in depressed and nondepressed students: Sadder by wiser? Journal of Experimental Psychology: General, 108, 441-485.

Benedict, J. O., AYres, J. B. (1972). Factors affecting conditioning in the truly random control procedure in the rat. Journal of Comparative \& Physiological Psychology, 78, 323-330.

Dickinson, A., Shanks, D., \& Evenden, J. (1984). Judgement of actoutcome contingency: The role of selective attribution. Quarterly Journal of Experimental Psychology, 36, 29-50.

Neunaber, D. J., \& Wasserman, E. A. (1986). The effects of unidirectional versus bidirectional rating procedures on college students' judgments of response-outcome contingency. Learning \& Motivation, 17, 162-179.

Rescorla, R. A. (1968). Probability of shock in the presence and absence of CS in fear conditioning. Journal of Comparative \& Physiological Psychology, 67, 504-509.

(Manuscript received May 13, 1991.) 